\title{
Medical Issues through Idiomatic Perspective
}

\author{
Natalya Zavyalova ${ }^{1}$ \\ ${ }^{1}$ Ural Federal University (UrFU), Russian Federation \\ Correspondence: Natalya Zavyalova, Mira str. 19, Ekaterinburg, 620002, Russian Federation. E-mail: \\ N.A.Zavialova@urfu.ru
}

Received: June 20, 2014 Accepted: July 28, 2014 Online Published: September 28, 2014

doi:10.5539/ass.v10n20p155

URL: http://dx.doi.org/10.5539/ass.v10n20p155

\begin{abstract}
Medical issues are complex and multifarious. My concern is the way medical professionals discuss health issues with patients. My research is focused on the domain of successful "patient-medical professional" communication. I assume that repeated usage of national standardized communicative formulae, idioms mainly, have a direct impact on a general well-being of a patient. With the example of language idiom representations and omnibus survey I concentrate on the most stable human society ways of expression, which should be taken into consideration by medical professionals. With the help of the on-line electronic linguistic corpuses of Russian and Chinese I identify tendencies common to Russian and Chinese patients. The research results have been processed into a database, marked with the Rospatent Certificate (№ 2013620397, dated 03/13/2013. Rightholder: Limited Liability Company 'Content-Press' (RU). First Author: Yakovlev Igor Gennadievich (RU). Second Author: Zavyalova Natalya Alekseevna (RU)).
\end{abstract}

Keywords: patient, medical professional, dialogue, communication, culture, omnibus survey, idiom

\section{Introduction}

The problem of 'patient-medical professional' dialogue has been critically viewed in a number of distinguished scholars of today. B. H. Hecht rightfully assumes the crucial role of communication in role-model of present-day GPs: 'In today's environment of fragmented mass media and popular technologies, GPs are losing the battle on how people perceive them' (Hecht, 2014). Bahrami et al. highlight the relevance of organizational climate for hospital employees, which results in effective 'medical professional-patient' interaction (Bahrami, Taheri, \& Montazeralfaraj, 2013). Y. Smulders highlights effective patient communication training challenges in the syllabus of modern medical colleges (Smulders, 2014). D. L. Alden et al. stress the importance of cultural targeting and tailoring for successful decision making in medicine: 'Patient decision aids are known to positively impact outcomes critical to shared decision making (SDM), such as gist knowledge and decision preparedness. However, research on the potential improvement of these and other important outcomes through cultural targeting and tailoring of decision aids is very limited. This is the case despite extensive evidence supporting use of cultural targeting and tailoring to improve the effectiveness of health communications' (Alden et al., 2014).

Bearing in mind the idea of cultural differences, I proceed to the analysis of effective "patient-medical professional" dialogue building strategies. Dialogues have been critically viewed throughout philosophical discourse, starting from the times of Plato and Gorgias to modern day philosophers and social workers. People need dialogues for self-identification. As S. Benhabib has objectively specified: 'To be and to become a self is to insert oneself into webs of interlocution; it is to know how to answer when one is addressed and to know how to address others' (Benhabib, 2002). The importance of electronic common people's dialogues through the Internet is stressed by Han: 'network communication and influences of grassroots and common people are enhancing increasingly, while the influence of authoritative information senders is weakening' (Han, 2014).

The idea of my research is to clarify the narrative strategies, expressed in words. However, the world of communication is vast. Which language items must be employed in "patient-medical professional" dialogue to increase the effectiveness of medical treatment? I proceed from the idea that idioms with number components can highlight key cognitive and cultural elements and they must constitute the basis of effective "patient-medical professional" communicative intercourse. I believe that such expressions assist to the progress of recovery or improving general well-being. Do common people really use idioms? Let's consider the following data and methods to prove it. 


\section{Data and Methods}

Stage 1. To prove the fact that ordinary people use idioms in their day-to-day communication I conducted an omnibus survey in cooperation with 'Yuri Levada Analytical Center' (Yuri Levada Analytical Centre, 2014). Levada-center carries out nationwide polls in Russian Federation, which are based on a representative sample of 1600 people over $18+$ from 130 sampling points across 45 regions of Russian Federation.

Our sample did not include the Chechen and Ingush Republics, as well as remote and sparsely populated region of the Far North (Nenets, Yamal-Nenets, Taimyr Autonomous Region, the Evenki Autonomous District, Kamchatka, Chukotka, Sakhalin Oblast). There were 9 Russian areas, totally excluded from consideration. The adult population in the excluded areas did not exceed 4\%. Residents of small settlements with a population of less than 50 people (about $0.8 \%$ of the adult population of Russia), the military (about $0.8 \%$ of the adult population of Russia), the person in custody or detention during the investigation (about $0.8 \%$ of the adult population of Russia), as well as homeless people (up to $1.5 \%$ of the adult population of Russia) were not included to the survey.

In each federal district independently all the primary sampling units were divided into strata according to their population number:

The city of more than 1 million people;

The town numbering from 500 thousand to 1 million people;

The town numbering from 100 thousand to 500 thousand people;

Urban settlements of up to 100 thousand people;

Villages.

These 5 categories were further subdivided into smaller groups. Given the characteristics of population distribution in the regions we formed 36 strata. The total sample (1,600 respondents) was distributed proportionally among all strata of the adult population in each stratum. The number of primary sampling units was determined from the restrictions on the average number of respondents in the same town/rural area (7-13 respondents).

All cities with a population of over 1 million people were included in the sample as independent statistical objects. In each of the remaining strata we selected randomly from 1 to 10 respondents (depending on the number of respondents who came on the stratum) from urban and rural areas. Number of profiles attributable to stratum was divided between the selected cities and rural areas equally.

Total sample included 130 urban and rural areas. The selection of survey points was done according to the following algorithm. In urban areas we made simple random sampling of the number of polling stations, including all precincts of the locality. In rural areas we randomly conducted the selection of villages and towns from the general list of all the villages and towns of the area. The number of selected polling stations (villages/towns) in urban areas (rural areas) was determined from the restrictions on the average number of respondents in one survey point (5-9 respondents).

In each primary sampling point we selected from 1 to 10 respondents (depending on the number of respondents who came to the city/rural survey points). Number of profiles attributable to city/rural area was divided between the selected survey points equally. Total sample included 280 survey points.

The selection of households was done according to the following pattern. In the selection of households we used a random route method (we included every 17 th household in areas with multi-storey buildings and each 5th household in areas with individual buildings).

The next stage concerned the selection of the respondents in the household. Respondents in the household were selected on a 'closest birthday' to 'to the control of sex and age and positive educational quotas'. Now let's discuss methods of survey and monitoring of interviewers. Research was conducted at the home of the respondent by personal interview.

For the control of interviewers we conducted:

Control roadmaps;

$15 \%$ of the control sample of interviews was interviewed by phone or repeat visit;

$20 \%$ of the respondents were interviewed by postal selective control (in cases where the checks by phone or re-visits were difficult to implement); 
We also included logical control data file using special computer programs.

Methods of data processing were as follows. The studies were coded, entered, cleaned out by random errors, omissions and inconsistencies, and we distributed our respondents by gender, age, education level, federal district, type of settlement, and according to the results of voting in the last national elections. The statistical error in the survey data used design sample does not exceed $3.4 \%$.

Our central survey question was as follows: 'Do you use common routine expressions, quotations from films and public speeches of famous people, bad language set expressions in your day-to-day life'? All these terms are referred to the domain of idioms in Russian. Parallel to this question Levada-center obtained the information about the professional status of the respondents (see table 1 and figure 1).

Table 1. Omnibus survey results, obtained in February, 2014 in Russian Federation by Yuri Levada Analytical center

\begin{tabular}{llllllll}
\hline & Total & businessman & CEO & manager & military man & office worker & worker \\
\hline Total & $\mathbf{1 6 0 3}$ & 58 & 74 & 277 & 26 & 192 & 388 \\
1, yes & $\mathbf{4 3 , 1}$ & 41,6 & 57,7 & 40,8 & 46,5 & 47,7 & 40,3 \\
2, no & $\mathbf{5 6 , 8}$ & 58,4 & 42,3 & 59,2 & 53,5 & 52,3 & 59,4 \\
\hline
\end{tabular}

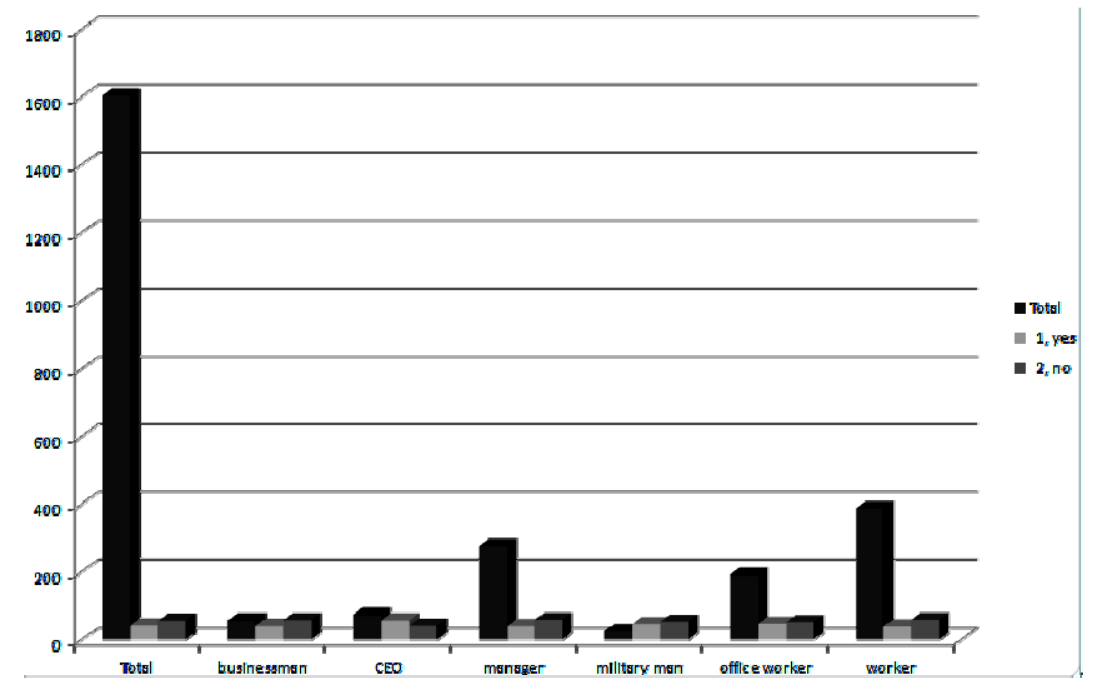

Figure 1. Omnibus survey results, obtained in February, 2014, in Russian Federation by Yuri Levada Analytical center

The table and the graph testify to the fact that idioms are used by $43.1 \%$ of modern Russian population. It is interesting to note that CEOs more willingly accept their usage of idioms, which can be explained by the fact that they provide a lot of instructions and guidelines to their employees.

Although the results were obtained on the material of the Russian language, I assume that all world languages have repeated constructions, which are very popular among native speakers.

Stage 2. The next stage of my analysis was devoted to on-line language corpus information extraction. With the help of the on-line electronic linguistic corpuses (Chinese corpus (Corpus of the Internet and business Chinese), Russian corpus (National Corpus of the Russian language)), I've singled out word stereotypes, which I view as a core component of hidden national standards of communication. The Chinese corpus provides an opportunity to trace back two types of usage in modern Chinese: the Internet frequency and business Chinese frequency. Thus, each item is given with a double frequency index. My primary concern is the 'number' idioms which represent the signal system of a speaker. Other idiom groups have been discussed in my previous research (Zavyalova, 2013. Economy of Wealth: National Stereotypes in Idiomatic Representation), (Zavyalova, 2013. Socio-cultural acquisition through idiomatic representation), (Zavyalova, 2013. Idiomatic Frequencies as Indicators of Socio-Cultural Acquisition). The Russian corpus gives the number of documents and entries of 
Russian idioms. Each idiom is provided with the number of documents and the number of entries indexes. Operating with huge masses of information, stored in corpuses, offers a reliable ground for making conclusions. The most frequent idioms are the ones, preferred by nations' representatives. I stress the idea that one and the same health care issue, discussed by doctors with different numbers, can result in different attitudinal markers on patients' behalf.

\section{Results}

Chinese are well-known for their love for accurate calculations and numbers. Corpus analysis has demonstrated that Chinese idioms aggressively employ numbers to describe the universe. Yìl bèn 3 wàn 4 lì4-'one brings ten thousand'-big revenues after small investment [the Internet-80; business Chinese-80]. Yìl bù4 dēng1 tiān1-'to reach the sky with one step'-have a meteoric rise [the Internet-102; business Chinese-69]. Yīl chén2 bù 4

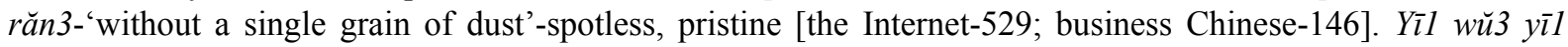
shi2-'one, five, one, ten'-every last detail [the Internet-341; business Chinese-78]. Sān1 sīl ér2 xing2-'to think 3 times before a walking'-think twice, think before leap [the Internet-65; business Chinese-77]. Bù 4 sān1 bù 4 sì-'neither 3, nor 4'-shady; neither one thing nor the other [the Internet-227; business Chinese-59]. Dú2 yīl wú2 èr4-'to be the only one, without the second one'-unparalleled, unique [the Internet-615; business Chinese-669]. Dī1 sānl xià4 sì-'to be lower than 3, to be lower than 4'-to be servile [the Internet-152; business Chinese-45]. Sān1 gù4 máo2 lú2-'3 visits to the house of an aristocrat'-persistence [the Internet-74; business Chinese-43]. Jiē1 èr4 lián2 sān1-'to put together 2 and 3'-one after another [the Internet-607; business Chinese-588]. Many prominent scholars of today stress the importance of idioms in day-to-day socio-cultural interaction. "In Chinese lexical system Chinese idioms are a typical unit. As an individual type in the domain of idioms, most Chinese idioms have some unique qualities. One of the design features of most Chinese idioms on the dimension of form characteristics is the four-character form the Chinese lexicon provides an exact number of the characters in such a unit. According to the statistics given in Zhou (2004), up to 95.57\% entries in Dictionary of Chinese Idioms are four characters. The uniformity in form regulates to a large extent some other linguistic characteristics of Chinese idioms, specifically phonological and semantic distribution. Compatible with the rhythmical arrangement and prosodic features represented by the two-plus-two syllables, a great number of Chinese idioms consist of double substructures, mostly parallel with each other (Sun, 1989). Branded with a distinct national style, Chinese idioms mirror the esthetic pursuit of symmetry deeply embedded in oriental thinking" (Zhang et al., 2013).

Now I proceed to discussing safeguard lines of "patient-medical professional" dialogue with Chinese patients through idiomatic perspective. First and foremost, one should stay away from the number 'four' in Chinese, because it is homonymous with the word 'death': sì (four) vs. š̉ (death). Ironically even in day-to-day situations Chinese prefer to stay away from this unfortunate number.

Eternity, skillfulness, vigor and talents are associated by the Chinese with number ' 8 '. I highlight the significance of this number for medical treatment purposes. Why not use this number while discussing exercising or necessary medical routines with Chinese patients? Subconsciously they are sure to connect this number with vigor and general well-being. Bā1 miàn4 líng2 lóng2-'8 skillful features'-be a smooth operator, a perfect mixer [the Internet-118; business Chinese-56]. Bāl miàn4 wèil fêngl-'8 features of power and impressiveness'-impressive, powerful [the Internet-25; business Chinese-16]. Cái2 gāol bāa dŏu3-'a high talent of 8 dŏ ( business Chinese-24].

Other number pillars in communicating with Chinese patients are the number 'hundred' and 'thousand', meaning 'everybody/all', 'longevity', 'eternity'. Why not use it while discussing unpopular medical routines, stressing the idea that everybody is doing it? Băi3 găn3 jiāol ji2-'to be overwhelmed with 100 feelings'-to have mixed feelings [the Internet-440; business Chinese-193]. Băi3 nián2 dà2 ji2-'an event for 100 years'-a landmark event [the Internet-50; business Chinese-80]. Băi3 zhàn4 băi3 shèng4-'100 fights, 100 victories'-undefeatable [the Internet-122; business Chinese-49]. Băi3 zhé2 bù4 náo2-"100 breaks down, but never gives up'-indomitable [the Internet-197; business Chinese-240].

Qiān1 fāng1 băi3 ji4-'1000 methods, 100 ways'-do everything in one's power [the Internet-686; business Chinese-675]. Qiānl zăi3 yīl shí2-'one in a thousand-a very rare chance [the Internet-11; business Chinese-0]. Gè4 yŏu3 qiānl qiūl-'everyone has his 1000 autumns (seasons)'-each one has its strong points [the Internet-267; business Chinese-240].

Large numbers in China are often associated with wealth. Such positive connotations are also very conducive to general well-being of patients, who associate wealth and wealth spending with Confucian rules of conduct. 'In 
China, some scholars have argued that luxury spending is socially beneficial to equalise wealth, under the assumption that the total endowment of resources is a fixed amount. This argument is not only consistent with Confucianism but also might point to another lesser known side of Confucianism that the luxury spending of the rich can be regarded as a wealth-transferring mechanism. Furthermore, luxury spending was encouraged for purposes of enjoyment; it did not involve the consideration of power and protection. This is in sharp contrast to the extravagance of the European nobility; their intention was to maintain a hierarchical structure ...'the rich's luxury spending is regarded as a wealth-transferring mechanism, which is 'just like gambling in a room, the money does not flow out but circulates among the players' (Peng \& Chang, 2012).

Russian number stereotypes are of religious nature. All positive connotations are connected with the number "7". To measure seven times, to cut one time-to test something accurately before making the final decision [28 documents, 30 entries]. Seven Simons-a group of seven brave people [1 document, 1 entry]. Onions cure seven diseases-onions are very good for one's health [2 documents, 3 entries]. Beyond seven seas-very far [6 documents, 6 entries].

Russian folklore criticizes the idea of doing something alone. Thus, the number "1" must be avoided by medical professionals not to create the idea of loneliness to their patients. One is not a fighter in the field-to win a victory people must act in groups [60 documents, 65 entries]. One head is good, but two heads are better!-two people can develop a smarter decision that one person [16 documents, 19 entries].

\section{Discussion}

From the point of view of psychiatry idioms are viewed as emotional units, analyzed by left and right hemispheres in a pattern, similar to all nations. "Emotional words trigger activation in other areas of the LH, such as the amygdala, orbitofrontal cortex, and posterior cingulate gyrus, as well. These regions have been claimed to be part of the limbic system (see Figure 2), which plays a key role in emotion processing" (Abbassi, Kahlaoui, Wilson, \& Joanette, 2011). "The data from a large body of research based on behavioral, electrophysiological, and neuroimaging methodologies appear to converge in indicating that both hemispheres are involved in the processing of words with emotional meaning, albeit in different, and probably complementary, ways." (Ibid., 373).

\section{The Limbic System}

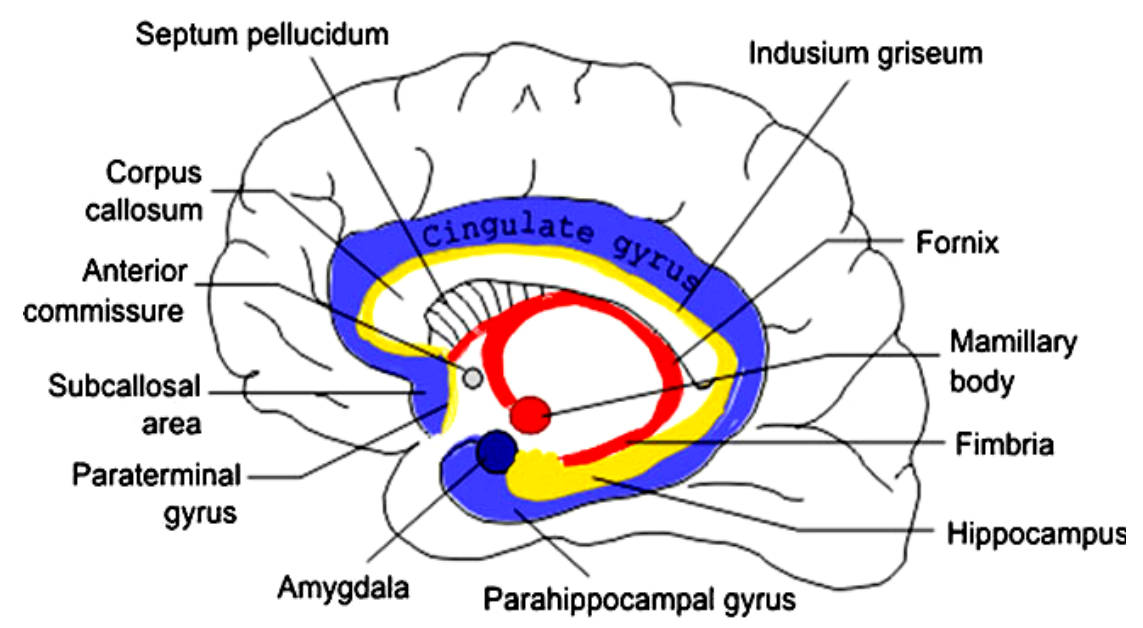

Limbic Gyrus Intralimbic Gyrus

Fornix \& Inner Arc

Figure 2. The limbic system

From Figure 3 we get a critical vision of numbers as significant elements of human-beings' lives, according to Serelex system of semantic proximity (Panchenko et al., 2013). Patients need numbers to describe their date of birth, security numbers and account numbers. Numbers directly relate to names, addresses and personal details. Besides this factual information there is much scope for implicit messages, hidden in numbers in the form of national stereotypes. According to D. L. Hamilton "The basis for all stereotyping is the differential perception of 
groups. Without such differentiation between groups, stereotyping cannot occur" (Hamilton \& Troiler, 1984). J.Wilson stresses that stereotypes “... have been shown to be remarkably resilient to change” (Wilson, 2006).

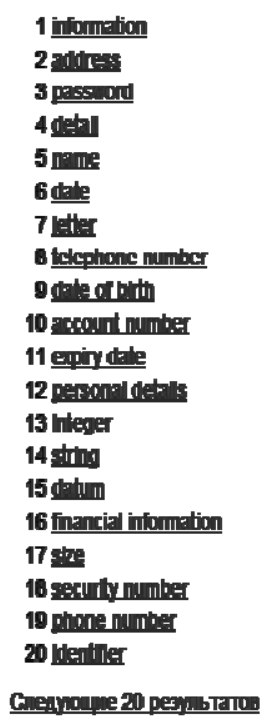

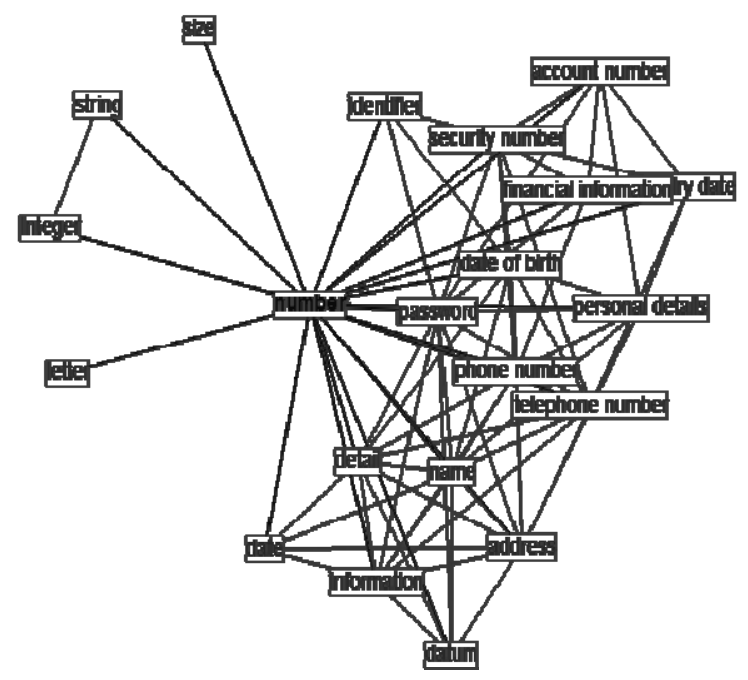

Figure 3. Serelex graph for the word 'number'

Now I proceed to the analyses of common structural features of idioms. As any information system the system of language can be described in terms of mathematical laws. I argue the axiom, supported by many scholars, that the system of language must be analyzed exclusively in linguistic terms. My central idea is that idioms and communicative formulae, as part of psycholinguistic system as such, should be analyzed within the framework of the principle of information maximum. This idea firstly appeared in the works by Shannon (Shannon et al., 1963) and later it was developed by Soviet and Russian scholars (Golytsin \& Petrov, 2005): "the system tries to find such response $y$, which enables the maximum of useful information about the given stimuli $x$ '.

$$
\mathrm{L}(\mathrm{X}, \mathrm{Y})=\mathrm{H}(\mathrm{Y})-\mathrm{H}(\mathrm{Y} / \mathrm{X})-\beta \mathrm{R}(\mathrm{X}, \mathrm{Y}) \rightarrow \max
$$

where H (Y)-the entropy of the system's conditions, H (Y/X)-the entropy of the system's mistakes and its reactions to outer stimuli, $\mathrm{R}(\mathrm{X}, \mathrm{Y})$-the average consumption of the system's resource in $\mathrm{Y}$ condition within all $\mathrm{X}$ environmental conditions, and $\beta$-the indicator of the system's deficit $(\beta=0$, when the system has an unlimited energy resource, и $\beta=1$ when the system has a very big energy deficit)" (Ibid.) .

According to the described above principle, all informational systems develop within 3 main strategies:

\section{THE PRINCIPLE OF INFORMATION MAXIMUM}

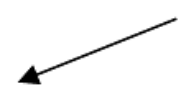

Tendency A Expansion

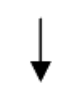

Tendency B

Idealization

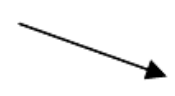

\section{Tendency $\mathrm{C}$}

\section{Resource Saving}

Figure 4. The principle of information maximum by Golytsin, Petrov

Expansion is realized through new varieties and numbers of environmental conditions, in which the analyzed system can exist. This tendency is sometimes called 'searching behavior' tendency H (Y). While idealization is concentrated on the tendency to minimize the system's mistakes entropy, idealization is sometimes known as the 'conservative behavior' tendency H $(\mathrm{Y} / \mathrm{X})$. It is achieved mainly through the repetition of the best variants. Why 
certain idioms are more frequent than others? Due to idealization strategy some idioms are selected by native speakers and repeated more frequently. I consider idiom frequencies as indicators of idealization strategy. Corpus analysis provides reliable data to analyze these indicators. Resource saving is realized in 2 possible ways: 1) minimizing the resource spent $\mathrm{R}(\mathrm{X}, \mathrm{Y})$; 2) minimizing the indicator of the system's deficit $\beta$ by means of resource growth. Each phraseology system develops such resource saving strategies as repetition, parallelism and borrowings from other languages, as well as some individual strategies, which are analyzed separately for each language.

Expansion, idealization and resource saving strategies in Chinese are realized on the principles of employing such numbers as 'hundred' and 'thousand', since they are the most frequent numbers in Chinese lexical system. Russian lexical system's expansion, idealization and resource saving strategies are centered around such numbers as 'seven' and 'three'.

The result of my omnibus survey, as well as the description of idiom frequencies and the analysis of expansion, idealization and resource saving strategies prove the fact that idioms are commonly used by people and patients all around the world. Thus, modern medicine has to take into consideration these communicative formulae. Besides, it is possible to target cultural stereotypes while analyzing idioms to identify national taboos, which work subconsciously within cognitive structures of national representatives.

\section{Conclusion}

Modern communication relies heavily on cultural targeting and tailoring. My central idea is that modern medicine must follow this practice, implementing science data, obtained from corpus studies. Successful communicative formulae with numbers 'eight', 'hundred' and 'thousand' are sure to boost general well-being, vigor and vitality of Chinese patients. One should also bear in mind the fact, that 'hundred' and 'thousand' in China develops deep religious implications, based on Confucian concepts of wealth and wealth-spending. However, in Russian culture the number 'one' creates the idea of loneliness; the number 'seven' roots from religious background of traditional Russian church.

The results of the analyses stress two fundamental outcomes: 1) common psycholinguistic and neurolinguistic mechanisms of idiom comprehension by two hemispheres (right and left), which can be deducted from common brain function mechanisms; 2) common mechanisms of expansion, idealization and resource saving. My research has demonstrated that it is possible to carry out the research of idioms along the lines of information theory.

My study is limited to Russian and Chinese. But I assume that the same practice is applicable to patients of other origins, as well, since every culture has repeated communicative structures. The results of my survey are applicable at 2 levels. At theoretical level I developed a new approach to targeting patients' cultural background. In practice this results in the creation of a more positive psychological atmosphere for patients during medical treatment. The process of cultural identification is hard and bound with countless obstacles: 'To the extent that cultural identification anchors the self-system and implicates a wide range of psychological processes, a perception of cultural identification may facilitate social understanding. As such, cultural identification may be actively discerned in social interactions. Among a group of friends, a perception of cultural identification would be relatively straightforward through intimate knowledge of one another. One intriguing question is whether people with no knowledge of one another are able to discern others' cultural identification' (Hamamura et al., 2013).

In practice the results of this study can be implemented in a special medical socio-cultural dictionary, where the most frequent idioms are given as social stereotypes and the most powerful symbolic tools of influence and manipulation. The practical implications of my study lie within the domain of social influence area, driven by communicative idiomatic stereotypes and the problem of meaning in sociology (see Berezin, 2014). The theoretical value of this research is the expansion of idiom status, whose role for the society analysis has been minimized to purely linguistic phenomena. I proceed from the idea that idioms are social in nature. Thus, their careful analysis adds to the profound understanding of social life.

Since language governs our mindset and intelligence I conclude that it has a direct impact on our health system. Understanding of cognitive mechanisms behind national intelligences is of vital importance. Psychologists define intelligence in many ways. I entirely support the propositions provided by Mark M. Lowenthal in his article 'A Disputation on Intelligence Reform and Analysis: My 18 Theses'. His main idea, relevant to this article is as follows: 'The core function of intelligence analysis is the ability to think interesting thoughts, to see beyond the apparent facts, to bring to bear expertise, and to write the results in a clear and compelling fashion' (Lowenthal, 2013). 
The atmosphere of constructive dialogue, based on culture awareness, is sure to support recovery of a patient, creating comfortable psychological environment and positive symbols.

\section{References}

Abbassi, E., Kahlaoui, K., Wilson, M. A., \& Joanette, Y. (2011). Processing the emotions in words: The complementary contributions of the left and right hemispheres. Cognitive, Affective and Behavioral Neuroscience, 11(3), 372-385. http://dx.doi.org/10.3758/s13415-011-0034-1

Alden, D. L. A., Friend, J. B., Schapira, M. C., \& Stiggelbout, A. D. (2014). Cultural targeting and tailoring of shared decision making technology: A theoretical framework for improving the effectiveness of patient decision aids in culturally diverse groups. Social Science and Medicine, 105, 1-8. http://dx.doi.org/10.1016/j. socscimed.2014.01.002

Amin, B. M., Ghasem, T., Razieh, M., \& Tafti, A. D. (2013). The Relationship between Organizational Climate and Psychological Well-Being of Hospital Employees. World Journal of Medical Sciences, 9(1), 61-67.

Benhabib, S. (2002). The Claims of Culture: Equality and Diversity in the Global Era (p. 15). Princeton University Press.

Berezin, M. (2014). How Do We Know What We Mean? Epistemological Dilemmas in Cultural Sociology. Qualitative Sociology. Springer Science + Business Media New York, 2014. http://dx.doi.org/10.1007 /s11133-014-9276-x

Corpus of the Internet and business Chinese. (2014). Retrieved February 10, 2014, from http://corpus.leeds. ac.uk/query-zh.html/

Golytsin, G. A., \& Petrov, V. M. (2005). Social and Cultural Dynamics: Long-term Tendencies (Information Approach) (pp. 24-27). Moscow: KomKniga (in Russian).

Hamilton, D. L., \& Troiler, T. K. (1986). Stereotypes and stereotyping: An overview of the cognitive approach. In J. Dovidio, \& S. Gaertner (Eds.), Prejudice, discrimination, and racism (p. 134). Academic Press, Orlando.

Han, R. H. (2014). Commercialization of Chinese Youth Network Subculture and Its Social Effects. Asian Social Science, 10(9). http://dx.doi.org/10.5539/ass.v10n9p234

Hecht, B. H. (2014). The image of general practice: The revolution begins. British Journal of General Practice, 64(621), 190. http://dx.doi.org/10.3399/bjgp14X677897

Lowenthal, M. M. (2013). A Disputation on Intelligence Reform and Analysis: My 18 Theses. International Journal Intelligence and Counter Intelligence, 26, 31-37. http://dx.doi.org/10.1080/08850607.2013.732435

National Corpus of the Russian language. (2014). Retrieved February 10, 2014, from http://www.ruscorpora.ru/

Panchenko, A. A., Romanov, P. B., Morozova, O. A., Naets, H. A., Philippovich, A. B., Romanov, A. B., \& Fairon, C. A. (2013). Lecture notes in computer science (including subseries lecture notes in artificial intelligence and lecture notes in bioinformatics). 7814 LNCS: 837-840. 35th European Conference on Information Retrieval, ECIR 2013; Moscow; Russian Federation; 24 March 2013 through 27 March 2013; Code 96205.

Peng, H. P., \& Chang, M. C. (2012). The foundations of Chinese attitudes towards advocating luxury spending. European Journal of the History of Economic Thought, 19(5), 691-708. http://dx.doi.org/10.1080/09672567. 2010.540342

Shannon, C. E., \& Weaver, W. (1963). The Mathematical Theory of Communication (pp. 20-80). University of Illinois Press.

Smulders, Y. (2014). Training for Effective Patient Communication. JAMA, 311(13), 1355. http://dx.doi.org/10. 1001/jama.2014.1757

Sun, W. Z. (1989). A study on Chinese idioms (hanyu shuyuxue) (p. 77). Jilin: Jilin Education Press (in Chinese).

Takeshi, H., \& Wai, L. L. M. (2012). Discerning Cultural Identification from a Thinly Sliced Behavioral Sample. Personality and Social Psychology Bulletin, 38(12), 1697-1706. http://dx.doi.org/10.1177/01461672124 59362

Wilson, J. (2006). 'Unpacking' the OE: An exploration of New Zealand 'overseas experience' (p. 134). Lincoln University, Lincoln. 
Yuri Levada Analytical Center. (2014). Retrieved February 10, 2014, from http://www.levada.ru/eng

Zavyalova, N. (2013a). Economy of Wealth: National Stereotypes in Idiomatic Representation. Middle-East Journal of Scientific Research, 13(Socio-Economic Sciences and Humanities), 47-50.

Zavyalova, N. (2013b). Idiomatic Frequencies as Indicators of Socio-Cultural Acquisition. World Applied Sciences Journal, 27(Education, Law, Economics, Language and Communication), 439-444.

Zavyalova, N. (2013c). Socio-cultural acquisition through idiomatic representation. World Applied Sciences Journal, 27(Education, Law, Economics, Language and Communication), 445-449.

Zhang, H., Yang, Y. M., Gu, J. X., \& Ji, F. (2013). ERP correlates of compositionality in Chinese idiom comprehension. Journal of Neurolinguistics, 26, 89-112. http://dx.doi.org/10.1016/j.jneuroling.2012.05.002

Zhou, J. (2004). A study on the structure of Chinese lexicon (hanyu cihui jiegoulun) (p. 230). Shanghai: Shanghai Dictionary Press (in Chinese).

\section{Copyrights}

Copyright for this article is retained by the author(s), with first publication rights granted to the journal.

This is an open-access article distributed under the terms and conditions of the Creative Commons Attribution license (http://creativecommons.org/licenses/by/3.0/). 